\title{
Impact of Changing Administrative Boundaries on Development of Uttar and Dakshin Dinajpur Districts, West Bengal
}

Sk Ismaile ${ }^{+*}$ and Dr. Namita Chakma ${ }^{*}$

\begin{abstract}
Generally, new districts are formed to facilitate administrative expediency or ease of administrative connectivity in a much better way. Often it reduces the distance between the district headquarters and remote areas resulting in easy access to the district headquarters with investing less time and strain. Apparently, it becomes helpful to interact with the beneficiaries in implementing and monitoring the government schemes and programmes in the areas near the district headquarters and remote areas, which is essential for the overall development of a region. In the present study, a meso-level specific comparative analysis has been done at inter and intra district level on the basis of some selected socio-economic indicators (based on Census of India data sources) to understand the impact of reorganisation of the administrative boundaries on the development of Uttar and Dakshin Dinajpur, West Bengal, India.
\end{abstract}

Keywords: District Reorganisation; Development; Inter-Regional; Intra-Regional; West Bengal; India

\footnotetext{
${ }^{\dagger}$ Research Scholar, Department of Geography, The University of Burdwan, Burdwan, 713104, West Bengal, India ${ }^{*}$ Corresponding AuthorE-mail id: skismaile784@gmail.com

* Associate Professor, Department of Geography, The University of Burdwan, Purba Barddhaman-713104, West Bengal, India, Email: namitachakma@gmail.com

(C) 2021 Ismaile \& Chakma. This is an Open Access article distributed under the terms of the Creative Commons Attribution License (http://creativecommons.org/licenses/by/2.0), which permits unrestricted use, distribution, and reproduction in any medium, provided the original work is properly cited.
} 


\section{Introduction}

In recent years, various countries' central and local authorities have been involved in reorganisation or reconstitution of the local administrative boundaries for providing better civic amenities and public services, such as communication, healthcare, education, public administration, justice, etc. India is not an exception to this trend. In the last 28 years, most of the states of India have also gone through local government administrative reforms and districts reorganisation process. Out of the total 731 districts, 259districts were formed between 1991 and 2019. Earlier, there were only nine districts in Manipur state, but after the final declaration of seven new districts by the state, the total number of districts in the state now has become 16. There were only ten districts in Telangana state when it was bifurcated from the state of Andhra Pradesh; later on, 17 new districts were formed in 2016. As of now, this state has 31 districts in total. During the time of Independence, West Bengal was divided into 14 districts. After that, in each census decade (except 1961-71 and 1971-81) one or more new districts were created, and in the last census, the total number of districts came to 19. From 2011 to 2017, the State Government of West Bengal has formed five new districts (Aliporeduar, Jhargram, Kalimpong, Purba Barddhaman, Paschim Bardhaman) by editing and altering the former ones. Hence the number of districts in West Bengal has increased from 19 in 2011 to 23 in 2017.

Generally, new districts are formed for administrative expediency or ease of administration so that the distance between the district headquarters and remote areas are shortened, which, in turn, helps with better implementation and monitoring of government schemes and programmes and also maintaining law and order in remote areas as well as for overall development of the region. However, sometimes some political motives, various sociocultural factors, jurisdictional area and population size of the district also work behind it.
In general, the main reason behind district reorganisation is to improve the level of development in every corner of the district for its being shorter in area. Hence, the principal objective of this study is to analyse the progress of development after the reorganisation of the districts in the state of West Bengal. At the same time, it also tries to examine the pattern of interdistrict disparity before and after the reorganisation. In this context, both Uttar Dinajpur and Dakshin Dinajpur districts have been selected for the study. Though many districts were bifurcated and new districts were created from 1980 to 2017 , such as bifurcation of 24 Parganas district into North 24 Parganas and South 24 Parganas (1986), Purba Mednipore and Paschim Mednipore were created bifurcating the Mednipore district (2002). On the other hand, Aliporeduar, Purba Barddhaman, Paschim Barddhaman, Kalimpong, Jhargram districts were created from 2011 to 2017.

This study has purposefully avoided the newly created districts as the development scale could not be examined appropriately within a very short span of time. Both Uttar Dinajpur and Dakshin Dinajpur districts were separated just after the 1991 Census to easily access the census data from the 1991 Census to evaluate the blockwise development level before the district reorganisation. To study the post reorganisation scenario, block-wise secondary data could be accessed from the 2011 Census. So one can easily examine the changes in development level after reorganisation of the district in the last 20 years. Thus, in the present study, a meso-level spatial comparative analysis has been done based on some selected socio-economic parameters before and after reorganisations of the West Dinajpur district to understand its impact on socio-economic development in the last two decades.

The present study begins with a detailed review of the existing literature to identify the lacuna of the previous research, followed by the geographical and administrative description of the study area. The study then discusses the objectives of the present study and the 
methodology adopted for this research. The concluding remarks have been drawn after the thorough analysis of the results obtained from the examination of different sets of data. Afterwards, some suggestive measures have also been specified for the lagging areas.

\section{Literature Review}

Several countries have gone in for the reform of their administrative map under unstable conditions. Spatial patterns of administrative reorganisation at the international level have been identified by reviewing relevant literature on the subject matter. The turbulent history since World War-I necessitated extensive reforms in most European countries because of unprecedented population distribution, economic activity and transport technology (Blacksell, 1974).The administrative map of Roumania has been reformed almost twelve times since World Warl (Helin, 1967). Since the communist attainment to power in 1949, China's political map has undergone a series of fundamental changes (Ginsburg, 1952). New arrangements were designed specifically to concentrate power at the intermediate level. This had the dual advantage of being more local and at the same time, less distant from the centre.

Among the developing countries, India recast its administrative map on 1 November 1965. It was a grand reorganisation of the states on a linguistic basis; units smaller than the states were only marginally affected. However, it was indicated that some of the new administrations must review the number and territorial extent of the existing districts (Government of India, 1955). The Planning Commission had also suggested that even during the First Plan (1951$56)$, it might be useful for the state governments to review the size of the districts to achieve efficient implementation of development programmes. Hirst(1973) has examined the locational efficiency of nine proposed Provincial headquarters of Uganda and suggested a more efficient solution for administrative reorganisation. Administrative area reform thus displays an apparent spatial pattern. Most First World countries, belonging to the 'old realm', redesigned their administrative structures by consolidating the lowest administrative units into bigger ones. The Third World countries have generally continued with their structures, with some occasional ad hoc modifications, mostly in the nature subdivision of larger units into smaller ones (Krishan,1988).

Since independence, several researchers have already conducted many studies on the reorganisation of state and district boundaries in India. Parmeshwarn and Chattopadhyay (2014) stated the methodical perspective to form a new state. They also focused on the shortcomings of the 1956 Reorganization Commission's Report at the time of Indian state reorganisation post independence. According to them, the size of the state should have a limit-a maximum population size of $\mathbf{4 0}$ million for a state. This is because human development is inversely related to the population size of the state. They suggest that creating a new state needs to be looked at physiographic region, natural resources distribution, agro-climate and river basins, and population distributions and cultural characteristics of the proposed new state. Rao (2017) has assessed the district reorganisation of Telangana. He described that the Government of Telengana had formed 21 new districts to take the administration closer to the people. But the formation of the small district does not automatically lead to good and effective governance and quality services. Therefore, he had suggested some recommendations- the location of the district Headquarter has to be more accessible to the majority of its residents; delegation of decision making power to lowerlevel officials; merger of different departments which are involved in similar and integrated functions; and transfer of certain functions to the Panchayati Raj institutions and urban local bodies for effective administrations.

Singh (2008) studied the process of federalisation of India. It is argued that any further reorganisation of states should be based on a "cosmopolitan model of democracy" and should be anchored in theories of constitutionalism, consociationalism and multiculturalism. Kudaisya (2015) critically 
analysed the State Reorganisation Commission's Report (1956). In his book, he described why Jawaharlal Nehru's government forced to set up the State Reorganisation Commission (SRC). This book also discusses that language and culture plays a major role for the reorganisation of Indian states. In another chapter of the same book focuses on the advantages or disadvantages of smaller vs larger states. The author summarised the major proposals and problem faced by the Reorganisation Commission when reorganising different states in India. Biswas (1999) has documented the momentous changes in the administrative boundaries of West Bengal since the battle of Plassey. The period of 1757 to 1793 named by the author was 'The Transitional Stage'. In this phase, the author described that after the Plassey battle, how East India Company came into power in Bengal province and how revenue generation, criminal and civil changes occur. The phase, 1793-1916, has been described as 'Period of Development and consolidation'. In this phase, the author wrote about the jurisdiction changes under the East India Company.

After reviewing the available literature, it has been found that enormous work has been done on regional disparities and concentration of development parameters. But how the reorganisation process does affect the development of a region or district in West Bengal has not been systematically explored before.

West Bengal emerged as a new state after the partition of Bengal province during the independence of India. As a result of this, the district of Dinajpur was divided into two parts following the partition of the province of Bengal, one part being named West Dinajpur was included in the state of West Bengal in India (Vide Notification No.-u/of Crpc1898, Act V), and the other part remained as Dinajpur in East Bengal of East Pakistan (now Bangladesh). Approximately two-thirds of the total geographical area of the Dinajpur district was included in East Pakistan, and one third was within India. West Dinajpur district became one of the 14 constituent districts of the province of
West Bengal on and from 17.08.1947. The district consisted of one subdivision, viz. West Dinajpur subdivision with Balurghat, Kumarganj, Gangarampur, Tapan, Raiganj, Hematabad, Bangshihari, Kushmundi, Kalianganj, and Itahar police stations. On 14.07.1948, bi-furcating the West Dinajpur subdivision, two new Subdivisions (Raiganj and Balurghat) were constituted. Raiganj subdivision had been constituted with Raiganj, Hematabad, Bangshihari, Kushmundi, Kalianganj, and Itahar, and remaining police stations were constituted with the police stations included within Balurghat subdivision (Biswas, 1999).

After the formation of the states by way of merging smaller units into adjoining areas, it was observed that the states were unequal regarding population, resources, linguistic, ethnic and other factors. So, the Government of India had formed a State Reorganization Commission in 1956 (Kudaisya, 2015) to re-appropriate the States. The State Reorganization Commission with the provision of merger Act 1954, Chopra police station was formed with the entire local areas of the police station of Thakurganj and Chopra in Kishanganj subdivision of the Purnea district in the state of Bihar and included in the district of Darjeeling. Further, Islampur and Goalpokhar police station in the Kishanganj subdivision and Karandighi police station in the Kathiar subdivision of the Purnea district in the state of Bihar were also included in the district of Darjeeling. Later, these areas were transferred to West Dinajpur district and again transferred to Darjeeling district. Finally, 12 villages of Thakurganj Police station, which lie in the north of Mahananda River retained in Darjeeling district and remaining portions comprising of Goalpokhar, Chopra, Islampur, and Karandighi police stations were inducted into the newly formed subdivision Islampur under West Dinajpur District (Biswas,1999).

Considering its vast territory, West Dinajpur district was further bifurcated into Uttar (North) Dinajpur and Dakshin (South) Dinajpur with a view to appropriate administrative convenience with effect from 1st April 1992 (Vide Notification No. 177-LR/6M-\&/92, dated-28.02.1992. The 
district Uttar Dinajpur was divided into two subdivisions, (1)Raiganj Sadar subdivision comprising of Raiganj, Itahar, Hematabad, Kalianganj police stations and (2) Islampur subdivision comprising of Islampur, Chopra, Goalpokhar, Chakulia, and Karandighi police stations. On the other hand, Dakshin Dinajpur was divided into two subdivisions, namely (1) Balurghat, comprising of Balurghat, Hili, Kumarganj, Tapanpolice stations and (2) Gangarampur subdivision consisting of Gangarampur, Banshihari, Harirampur, Kushmundi police stations.

\section{The Study Area}

Both Uttar Dinajpur and Dakshin Dinajpur Districts came into existence in 1992 after the bifurcation of the West Dinajpur district. The areal coverages of Uttar Dinajpur and Dakshin Dinajpur districts are 3,142 sq. km. and 2,219 sq. km. Uttar Dinajpur district comprises two subdivisions Raiganj and Islampur (Raiganj being the District Head Quarters). There are nine community development blocks. The C.D. Blocks under Raiganj sub-division are Hemtabad, Itahar, Kaliaganj and Raiganj. C.D. Blocks under the Islampur subdivision are Chopra, Islampur, Goalpokhar-I, Goalpokhar-II and Karandighi. Dakshin Dinajpur District also subdivided into 2 subdivisions (Balurghat and Gangarampur) with 8 C.D. Blocks. The C.D. Blocks under the District Head Quarter Balurghat are Kumarganj, Tapan, Balurghat,Hili and Kushmandi, while Banshihari, Harirampur and Gangarampur C.D. Blocks belong to Gangarampur SubDivision (Figure1).

According to the Census of India, 2011, Uttar Dinajpur district stands at 15th position, and Dakshin Dinajpur is the least populated district in West Bengal. The percentage of the urban population of Uttar Dinajpur district has almost remained the same in the last decade $(12.1 \%)$

Composite Index has been calculated as follows:

Let $[\mathbf{X} \mathbf{i j}]$ be the data matrix.

$\mathrm{i}=1, \ldots \mathrm{n}$ (Number of area unit)

$j=1,2, \ldots k$ (Number of indicators) whereas a $1 \%$ increase in urban population has been found in the case of Dakshin Dinajpur district. Literacy rates in both districts are less than the state average (76.3\%).

\section{The Objective of the Study}

The objective of the present study is to analyse the impact of changes in administrative boundaries on the development of the Uttar Dinajpur and Dakshin Dinajpur districts of West Bengal, India.

\section{Materials and Methods}

To understand the overall development scenario before and after the reorganisation of the West Dinajpur district, the block-wise aggregate index has been calculated with some selected socioeconomic indicatorsfrom two census years, 1991 and 2011. We have used both the social and economic indicators of development depending on the availability of the census data. Overall, 23 indicators have been selected from different sectors (demographic condition, work participation rate, education facilities, health care service facilities, and basic amenities), and a composite index (Narain et al., 2011)has been prepared. To compare the situation before and after reorganisation, an aggregate index has been calculated for 1991 and 2011 separately for all the blocks of Uttar Dinajpur and Dakshin Dinajpur districts and ranked them accordingly. To understand the level of disparity in terms of the overall development of 17 blocks, quadrant positional analysis has been done from PC1 and PC2. The PC1 axis is the first principal direction along which the samples show the largest variation in the principal component analysis (PCA). The PC2 axis is the second most important direction, and it is orthogonal to the PC1 axis. Arc GIS (Version-10.2.1) software has been used for mapping purposes. Since [Xij ] comes from different population distributions and might be recorded in different units
of measurement, they are not quite suitable for simple addition for obtaining the composite index. 
Therefore,

[Xij] is

$$
\begin{aligned}
& \text { transformed } \\
& {[\boldsymbol{Z} \boldsymbol{i} \boldsymbol{j}]=\frac{\boldsymbol{X} \boldsymbol{i} \boldsymbol{j}-\overline{\boldsymbol{X}} \boldsymbol{j}}{\boldsymbol{S} \boldsymbol{j}}}
\end{aligned}
$$

as

follows:

Where, $\bar{X} \mathbf{j}=$ mean of the $\mathrm{jth}$ indicator, $\mathrm{Sj}=$ standard deviation of the jth indicator, $[\mathrm{Z} \mathrm{ij}]$ is the matrix of standardised indicators.

From [ $\mathrm{Z}$ ij] identify the best value of each indicator. Let it be denoted by Zoj. The best value will be either the maximum value or minimum value of the indicator depending upon the direction of the impact of the indicator on the level of development. For obtaining the Pattern of Development, calculate Pij as follows.

$$
\mathrm{Pij}=(\mathrm{Zij}-\mathrm{Zoj})^{2}
$$

The pattern of development $\mathrm{Ci}$ is given as : $\mathbf{C i}=\left[\sum_{j=1}^{k} \boldsymbol{P} \boldsymbol{i j} /(\boldsymbol{C} . \boldsymbol{V} .) \boldsymbol{j}\right]^{1 / 2}$ Where (C.V.)j is the coefficient of variation of the jth indicator in Xij

Composite Index $\mathrm{Di}$ is given by $\mathbf{D i}=\mathbf{C i} / \mathbf{C} \quad$ For $\mathrm{I}=1,2, \ldots . \mathrm{n}$

$$
\text { Where } \mathbf{C i}=\mathbf{C}+\mathbf{3 S} \quad \mathbf{C}=\text { Mean of } \mathbf{C i} \text { and } \mathbf{S}=\text { Standard Deviation of } \mathbf{C i}
$$

Aggregate Index $=\left(D_{1}+D_{2}+D_{3}\right) \ldots \ldots \ldots n$

The smaller value of the Aggregate Index will indicate a high level of development, and a higher value will indicate a lower level of development.
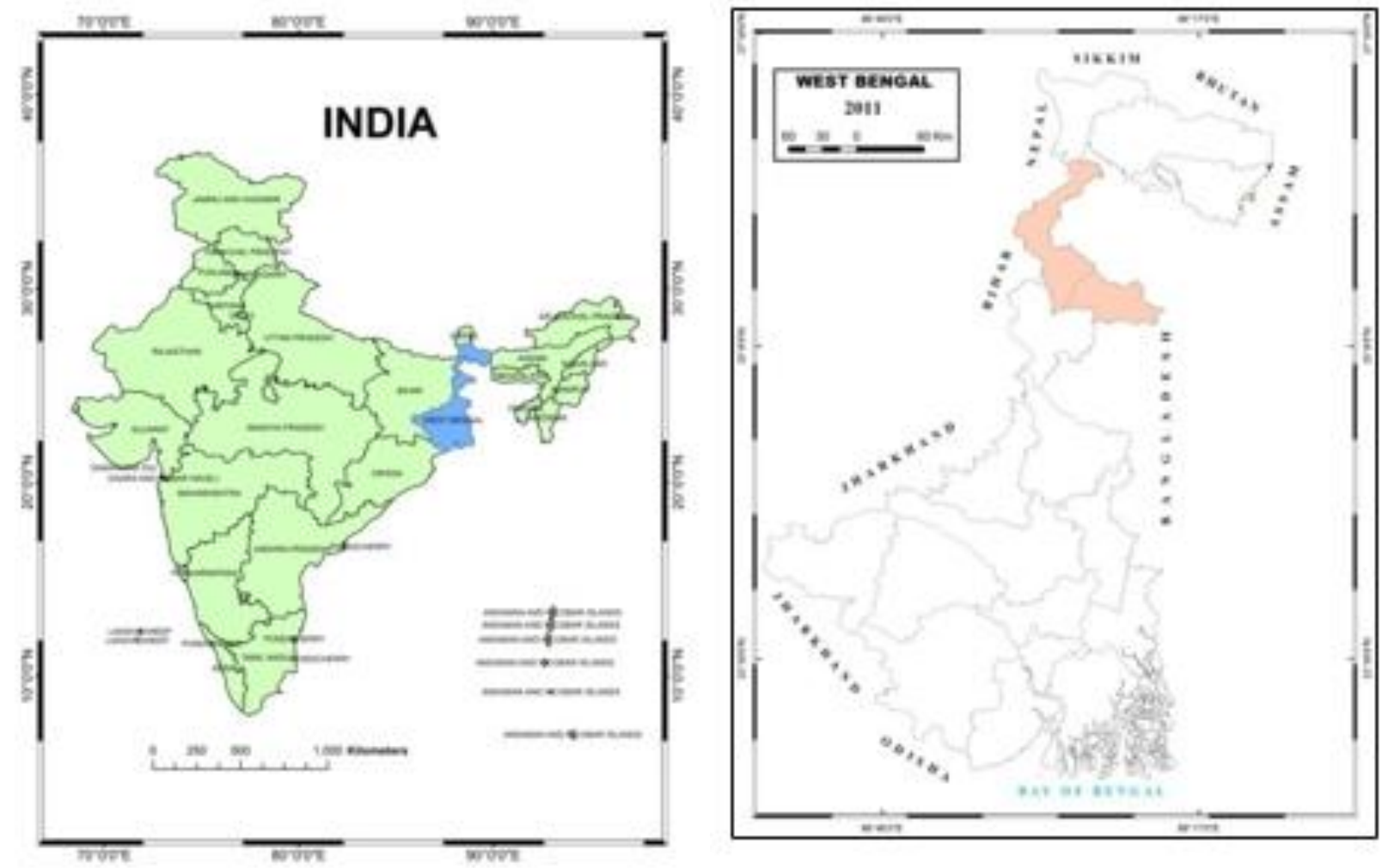


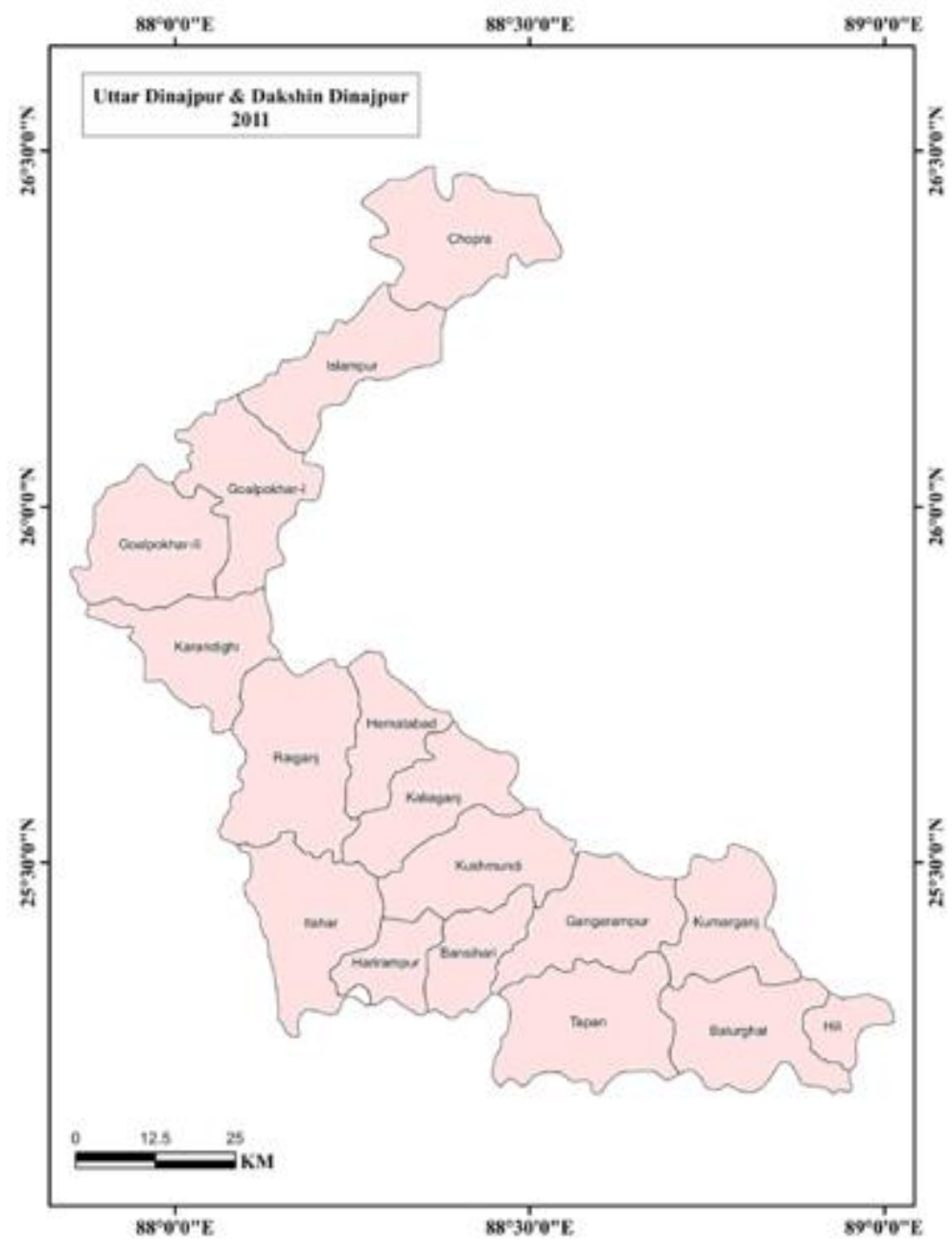

Figure 1: Location of the Study Area

Source: Authors

\section{Results and Discussion}

From Tables1 and 2, it has been found that among all the C.D. (Community Development) blocks, Balurghat was the most developed block in 1991. Being the district's headquarter with better infrastructural facilities, a high literacy rate, medical facilities, and the highest percentage of the working population made Balurghat in the leading position compared to other blocks of West Dinajpur. In 2011 Balurghat ranked 4th among all the C.D. blocks of Uttar and Dakshin Dinajpur districts, and Banshihari ranked first. The main reason behind the leading position of Bansihari block was that the most backward region Harirampur, which was once a part of Bansihari block, has been separated from Banshihari block. In 1991, among the top five ranked blocks, 2nd, 3rd, and 4thranked C.D. blocks were in Uttar Dinajpur district. Only two blocks were included in the Dakshin Dinajpur district. But at present, the picture is almost reverse. From Table 2, it is observed that among the 17 C.D. blocks, the top four ranked blocks are within Dakshin Dinajpur district. Only Itahar (5th rank) block is in the Uttar Dinajpur district. The aggregate index shows that Islampur, Goalpokhar-I, Goalpokhar-II, and Raiganj are less developed C.D. blocks, and no significant changes occurred in the last 20 years, though Raiganj has slightly improved its position from rank 14th to 10 th (table 2). Low sex ratio, low literacy rate, lower working population percentage, the higher gender gap in literacy, and poor infrastructure facilities compelled these C.D. blocks to remain in the bottom position.

From the above analysis, it has been observed that after the bifurcation of the West Dinajpur 
district, most of the C.D. blocks of Dakshin are huge differences between the 1st ranking Dinajpur district have relatively improved in C.D. block and last ranking C.D. block, which comparison to the C.D. Blocks of Uttar Dinajpur indicates a high level of disparity between these district. The aggregate index shows that there blocks (Figures 2, 3).

Table 1: Aggregate Index and Rank of C. D. Blocks of West Dinajpur District, 1991

\begin{tabular}{|c|c|c|c|}
\hline \multirow{17}{*}{$\begin{array}{c}\text { District } \\
\text { West Dinajpur }\end{array}$} & C.D. Blocks & Aggregate Index & Rank \\
\hline & Chopra & 2.244 & 6 \\
\hline & Islampur & 2.807 & 15 \\
\hline & Goalpokhar I & 3.565 & 16 \\
\hline & Goalpokhar II & 2.725 & 14 \\
\hline & Karandighi & 2.218 & 4 \\
\hline & Raiganj & 2.631 & 13 \\
\hline & Hemtabad & 2.023 & 3 \\
\hline & Kaliaganj & 2.452 & 10 \\
\hline & Itahar & 2.017 & 2 \\
\hline & Kushmundi & 2.285 & 7 \\
\hline & Kumarganj & 2.520 & 12 \\
\hline & Hili & 2.309 & 8 \\
\hline & Balurghat & 1.755 & 1 \\
\hline & Tapan & 2.464 & 11 \\
\hline & Bansihari & 2.393 & 9 \\
\hline & Gangarampur & 2.220 & 5 \\
\hline
\end{tabular}

Source: Census of India, 1991

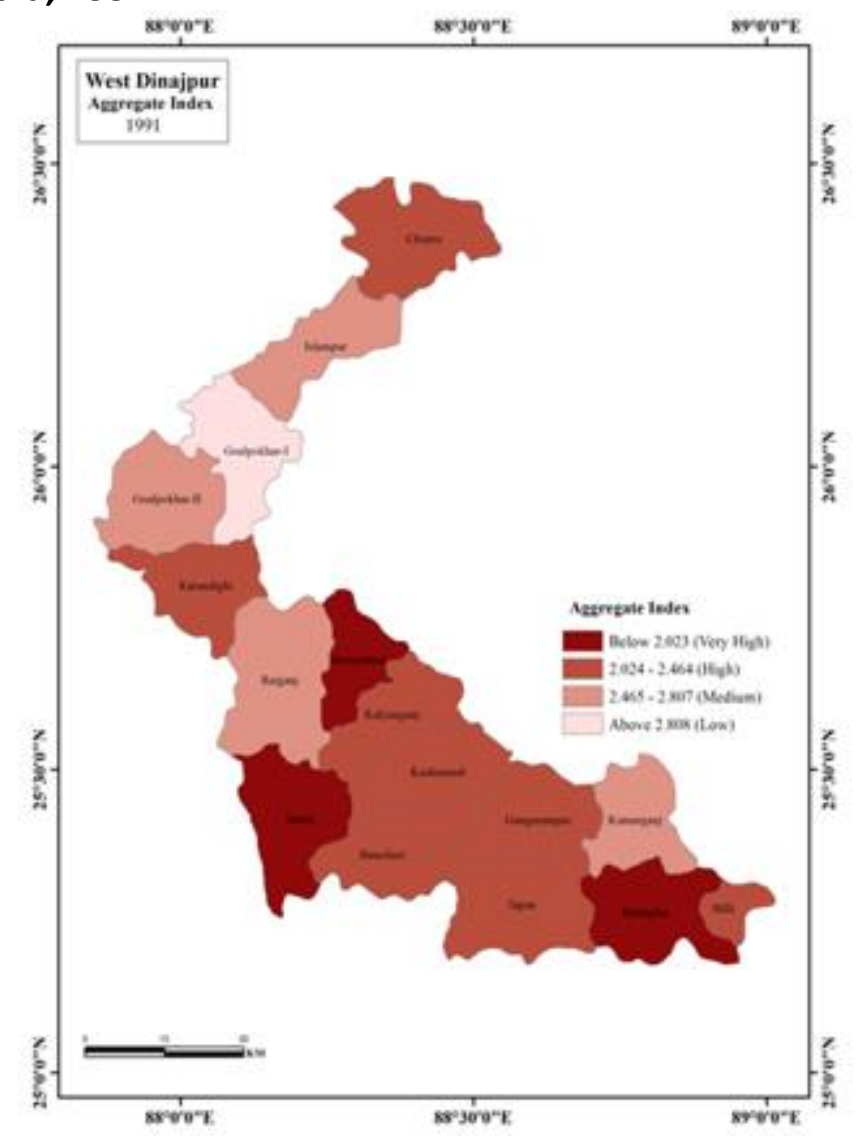

Figure 2 Aggregate Index of C. D. Blocks of West Dinajpur District, 1991 Source: Census of India, 1991 
Table 2: Aggregate Index and Rank of C. D. Blocks of Uttar Dinajpur and Dakshin Dinajpur Districts, 2011

\begin{tabular}{|c|c|c|c|}
\hline \multirow{10}{*}{$\begin{array}{c}\text { District } \\
\text { Uttar Dinajpur }\end{array}$} & C.D. Blocks & Aggregate Index & Rank \\
\hline & Chopra & 6.414 & 12 \\
\hline & Islampur & 7.325 & 17 \\
\hline & Goalpokhar I & 6.997 & 16 \\
\hline & Goalpokhar II & 6.496 & 13 \\
\hline & Karandighi & 6.242 & 11 \\
\hline & Raiganj & 5.847 & 9 \\
\hline & Hemtabad & 4.665 & 6 \\
\hline & Kaliaganj & 5.470 & 8 \\
\hline & Itahar & 4.502 & 5 \\
\hline \multirow[t]{8}{*}{ Dakshin Dinajpur } & Kushmundi & 6.8 & 14 \\
\hline & Gangarampur & 6.15 & 10 \\
\hline & Kumarganj & 5.283 & 7 \\
\hline & Hili & 4.098 & 3 \\
\hline & Balurghat & 4.445 & 4 \\
\hline & Tapan & 3.9 & 2 \\
\hline & Bansihari & 1.925 & 1 \\
\hline & Harirampur & 6.873 & 15 \\
\hline
\end{tabular}

Source: Census of India, 1991

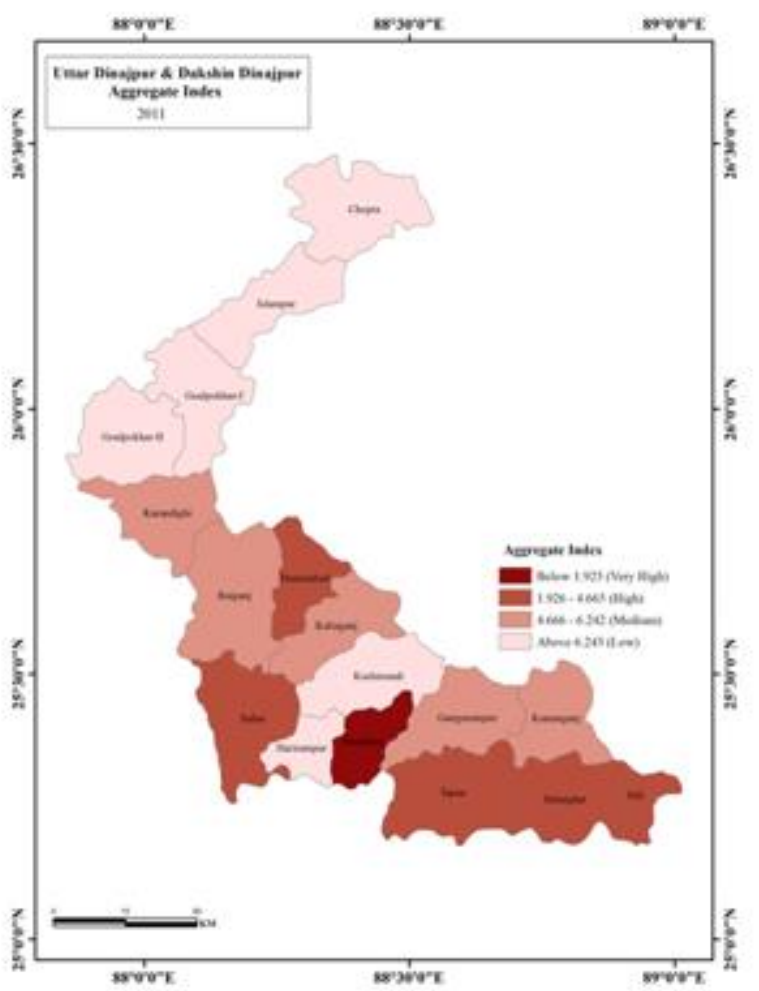

Figure 3: Aggregate Index of C. D. Blocks of Uttar and Dakshin Dinajpur Districts, 2011 Source: Census of India, 2011

To understand the level of disparity in terms of overall development of 17 C.D. blocks of the Uttar and Dakshin Dinajpur districts, Print Score 1 and Print Score 2 have been calculated from
PC1 and PC2 for both the census years (Tables 3 and 4). As far as the development level is concerned, in 1991, Balurghat, Kalianganj, Raiganj, Karandighi, and Hili C.D. blocks are 
found in a better position $(+,+)$. The quadrennial position $(+,-)$ of Bansihari, Kumarganj, Tapan, Hematabad, Chopra, and Goalpokhar-I indicate them as moderately developed C.D. blocks of West Dinajpur District in 1991. In 2011 only Balurghat and Hili Blocks showed their positions remaining unchanged. In contrast,Kalianganj, Raiganj, and Karandighi C.D. blocks in a highly developed category in 1991, in 2011 Kalianganj and Raiganj fell in moderate levelKarandighi fell in the low-developed category in quadrant positional analysis (Figures 4 and 5). On the other hand, Tapan, Kumarganj, and Hematabad C.D. blocks upgraded their position from moderately developed $(+,-)$ zone in 1991 to developed $(+,+)$ zone in 2011 . The main reasons behind this are Tapan, Kumarganj, and Hematabad C.D. blocks have improved much in education facilities, health facilities, and other infrastructure facilities in the last twenty years compared to other C.D. blocks of Uttar and Dakshin Dinajpur districts.

It has also been observed from the quadrant analysis in 1991 that Itahar, Islampur, Goalpokhar-II, Gangarampur, and Kushmundi C.D. blocks were categorised under the low developed (-, -) zone. However, in 2011 Goalpokhar-II, Gangarampur and Kushmundi upgraded their positions, only the Islampur C.D. block remained unchanged due to a lower female-male ratio (941), lower literacy rate (61.13\%), the higher gender gap in both literacy rate(15.72\%) and work participation rate (33.20\%) and prolonged improvement in other infrastructural development categories.

Table 3: Extraction of PC1 and PC2, West Dinajpur District, 1991

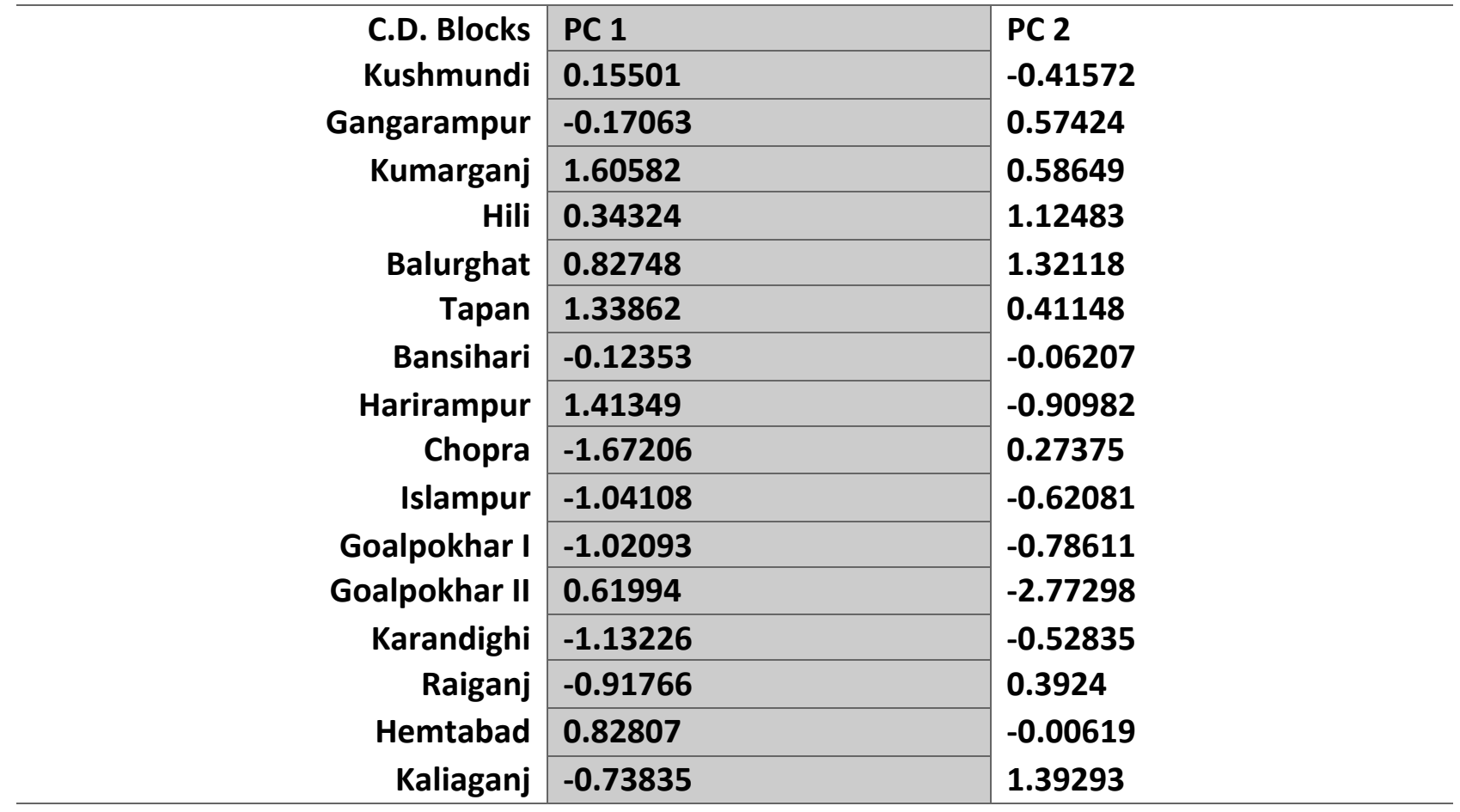

Source: Census of India, 1991 
Table 4: Extraction of PC1 and PC2, Uttar and Dakshin Dinajpur Districts, 2011

\begin{tabular}{r|c|c|} 
C.D. Blocks & PC 1 & PC 2 \\
\cline { 2 - 3 } Raiganj & 0.52007 & 1.03513 \\
Kaliaganj & 0.18008 & 0.54353 \\
\cline { 2 - 3 } Hemtabad & -0.40204 & 0.33493 \\
Itahar & -0.32084 & -0.08052 \\
Bansihari & 0.24829 & -0.47838 \\
\cline { 2 - 3 } Kushmundi & -0.06998 & -1.53055 \\
Islampur & -1.23758 & -0.2424 \\
Karandighi & 0.25033 & 0.86801 \\
\cline { 2 - 3 } Chopra & -1.05735 & 1.25269 \\
\cline { 2 - 3 } Goalpokhar I & -0.70578 & 1.95593 \\
\cline { 2 - 3 } Goalpokhar II & -0.82419 & -1.35199 \\
Gangarampur & -0.1301 & -1.39066 \\
\cline { 2 - 3 } Kumarganj & 0.05649 & -0.59595 \\
\cline { 2 - 3 } Tapan & 0.15316 & -0.72817 \\
Balurghat & 0.11139 & 0.25552 \\
\cline { 2 - 3 } Hili & 3.22805 & 0.15288
\end{tabular}

Source: Census of India, 2011

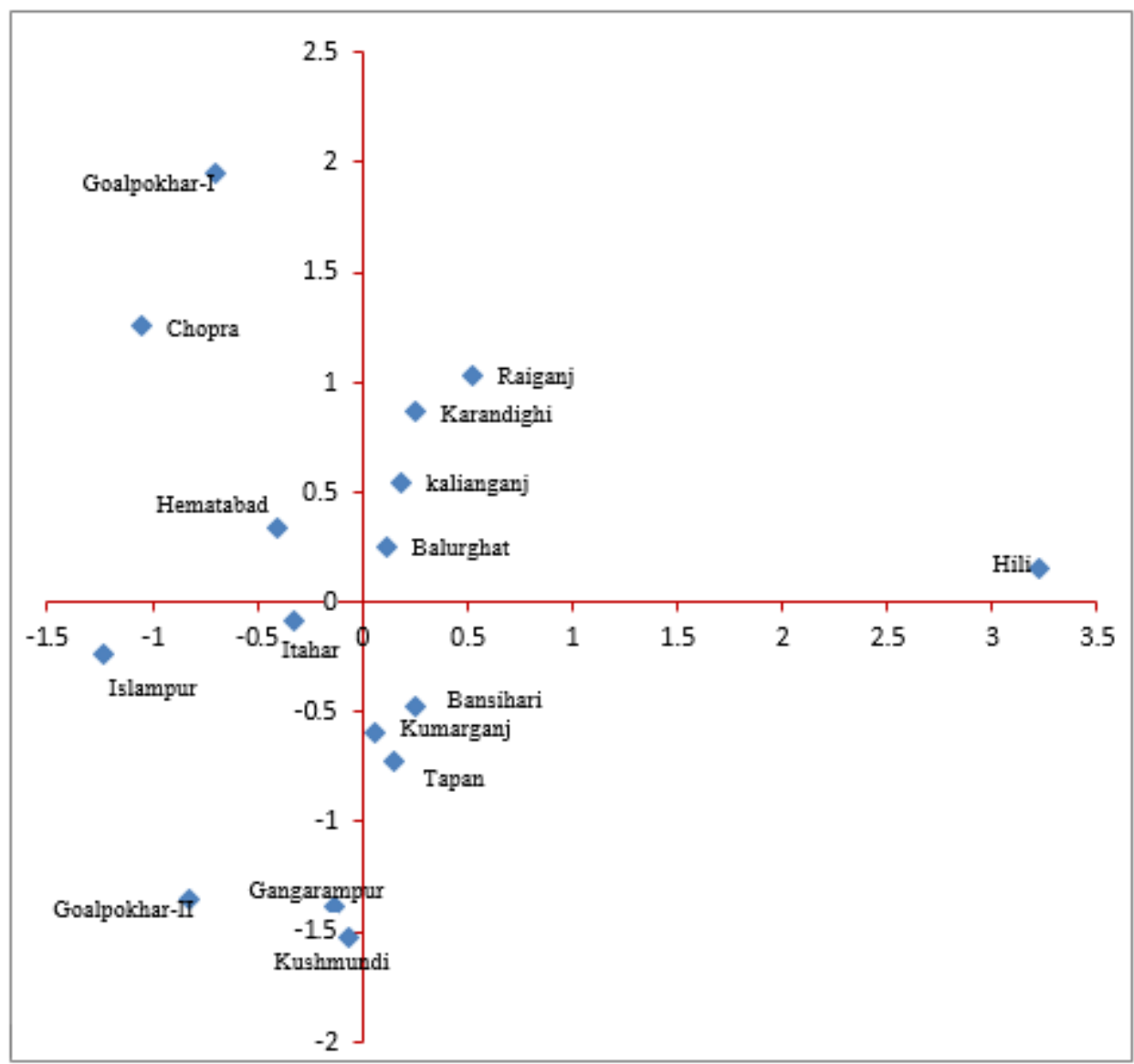

Figure 4: Blockwise Development level of West Dinajpur district using Quadrant Positional Analysis, 1991 


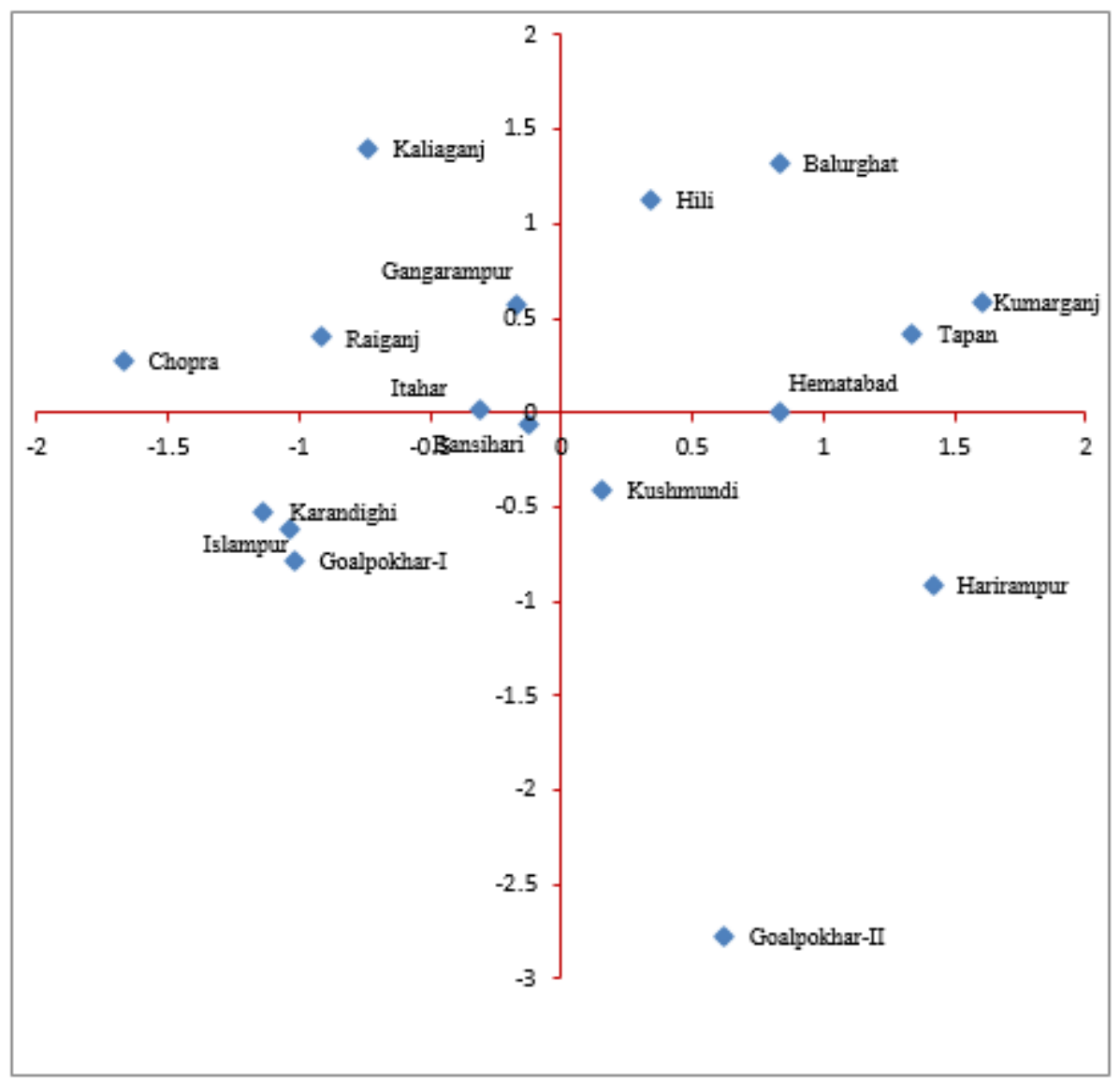

Figure 5: Block wise Development level using Quadrant Positional Analysis, 2011

Source: Census of India, 2011

\section{Conclusion}

Several changes have already been taken place in the administrative atlas of West Bengal and the West Dinajpur district,which further bifurcated into Uttar Dinajpur and Dakshin Dinajpur districts. A well-administered district with a manageable jurisdictional area and population size is the cornerstone of a wellgoverned state. Large areas and the large population size of any district always have some disadvantages for implementing and monitoring various government schemes and the execution of developmental programme activities. Districts are always bifurcated to implement the development programmes and schemes of the Government in a better way.

Thus, the demarcation of district boundaries should reorganise scientifically or systematically to achieve a balanced economy, equal natural and human resource distribution, balance in area and population, manageable distance from district headquarter and the remote regions, and better connectivity among the population of different socio-economic groups.

From the present study, it has been clearly observed that most of the C.D. blocks of Uttar Dinajpur and Dakshin Dinajpur districts have been upgraded their position in terms of development level after the bifurcation of West Dinajpur district. Though, it is evident that the uneven and unequal distributions of population and resources between Uttar Dinajpur and Dakshin Dinajpur districts have created a massive regional disparity among the C.D. blocks in the districts. Inter block-level evaluations of the development level of Uttar Dinajpur and Dakshin Dinajpur districts have clearly identified leading and lagging areas within the districts.

Some suggestive measures for the lagging areas in both the districts have been specified as follows:

- Redressal of educational inequalities: Accessibility of rural schools is still a 
significant problem in Uttar Dinajpur and Dakshin Dinajpur districts. Many students residing in remote areas have to travel a long distance of $4-6 \mathrm{kms}$ to attend upper primary and secondary schools. This problem mainly affects the Islampur C.D. block. School infrastructures are very poor, and the pupil-teacher ratio is also very high in Uttar and Dakshin Dinajpur districts. To strengthen educational infrastructure in Uttar and Dakshin Dinajpur districts will thus require establishing a substantial number of new schools and by extension of classrooms and new teacher recruitments for the existing ones. Many high school and college students are firstgeneration learners whose families hitherto lack an educational environment. Hence, career guidance centres need to be established at the school institution to counsel them on their future choice of subject and carrier options.

- Improvement in physical and health care infrastructures: Both Uttar Dinajpur and Dakshin Dinajpur have very poor transport and communication networks. In Raiganj, the headquarter of Uttar Dinajpur district,manybasic facilities still need to be upgraded. Islampur subdivision area is dependent on the adjoining Kishanganj area in Bihar for major communication linkage. This infrastructural limitation hampers the socio-economic development in the Uttar Dinajpur district. Although a large number of rural roads in Uttar Dinajpur and Dakshin Dinajpur districts have recently been constructed with the Pradhan Mantri Gram Sadak Yojana (PMGSY), was launched by the Government of India. The main objective of Pradhan Mantri Gram Sadak Yojana is to connect all unconnected habitations in the rural areas through the construction of all-weather roads with necessary culverts and cross-drainage structures in a manner that will provide the most economical and efficient connectivity, thus promoting access to economic and social infrastructure. Though some remote villages in Tapan, Hili, Islampur, and Chopra C.D. blocks continue to face road network problems. Thus, the road network in the districts will have to be upgraded and expanded for a better inter-connectivity amongst the villages and intra-connectivity from villages to block headquarters, district headquarters, and vice-versa.

Sustainable public health care requires sufficient staffing and additional Health Care and Clinic infrastructure. With the increasing population and proportionate increase in the number of patients, the primary health care systems in Uttar Dinajpur and Dakshin Dinajpur are currently unable to provide adequate health care coverage. The available bed strength in many Block Primary Health Centres (BPHCs) is highly insufficient, and the existing strength of doctors and nursing staff is not at all compatible with providing service to the growing numbers of patients. This compels many indoor patients to shift to nearby private hospitals or subdivisional and district hospitals far away from their residences. Institutional deliveries are still relatively rare, leading to a high percentage of pre-natal, neo-natal and post-natal mortality among mothers and infants in Uttar Dinajpur and Dakshin Dinajpur districts. Besides these, the district hospital of Raiganj, which has been upgraded in name only, continues to function within the infrastructure of a subdivisional hospital. Hence, upgraded and compatible healthcare infrastructure, both in human power and in devices and equipment in Uttar and Dakshin Dinajpur districts, will have to be made to provide better health care facilities to the people.

\section{References}

Biswas, K.R. (ed.). (1999). A Summary of the Changes in the Jurisdiction of Districts in West Bengal 1757-1916. Calcutta, WBDG

Blacksell, M. (1974). A new political map for England and Wales. Geoforum, 5(3), 63-67. https://doi.org/10.1016/0016-7185(74)90090-6 
Census of India. (1991). District Census Handbook, West Dinajpur.Village and Townwise primary census abstract, West Bengal:

Directorate of Census Operations. http://lsi.gov.in:8081/jspui/bitstream/1234567 89/5328/1/35281_1991_WES.pdf

Census of India. (2011). District Census Handbook, Uttar Dinajpur.Village and Town Directory, West Bengal: Directorate of Census Operations.

https://censusindia.gov.in/2011census/dchb/D CHB_A/19/1904_PART_A_DCHB_UTTAR\%20DIN AJPUR.pdf

Census of India. (2011). District Census Handbook, Dakshin Dinajpur.Village and Town Directory, West Bengal: Directorate of Census Operations.

https://censusindia.gov.in/2011census/dchb/19 05_PART_B_DCHB_DAKSHIN\%20DINAJPUR.pdf

Ginsburg, N. (1952). China's Changing Political Geography. Geographical Review, 42(1), 102117. doi:10.2307/211255

Government of India. (1955) Report of the States Reorganisation Commission. New Delhi: Government Printer.

Helin, R. A. (1967). The volatile administrative map of Rumania. Annals of the Association of American Geographers,57(3), 481502.https://doi.org/10.1111/j.14678306.1967.tb00617.x

Hirst, M. (1973). Administrative Reorganization in Uganda: Towards a More Efficient Solution. Area, 5(3), 177-181. http://www.jstor.org/stable/20000749 Krishan, G. (1988). The World Pattern of Administrative Area Reform. The Geographical Journal, 154(1), 93-99. doi:10.2307/633479

Kudaisya, G. (2015). Reorganisation of States in India. New Delhi, National Book Trust.

Narain, P., Bhatia, V.K., \& Rai, S.C. (2011). Pattern of Regional Disparities in Socioeconomic development inWest Bengal. Indian Society of Agricultural Statistics, 65(1), 27-35.
Parmeshwarn, M.P., \& Chattopadhyay, S. (2014). A Different Approach; Reorganisation of States. Economic \& Political Weekly, 45(42), 8186.

https://www.epw.in/journal/2014/42/notes/re organisation-states.html

Prakasa Rao, V. L. S. (1984) What is a viable administrative unit? Ann. Nat. Ass. Geogr., India 77-9.

Rao, G.B. (2017). Reorganisation of District in Telegana. Economic\& Political Weekly, 52(10), 70-76.

https://www.epw.in/search/site/reorganization \%20of\%20district\%20in\%20telengana

Singh, M.P. (2008). Reorganisation of States in India. Economic \& Political Weekly, 43(11) 7076.

https://www.epw.in/journal/2008/11/specialarticles/reorganisation-states-india.html

\section{Conflict of Interest}

This manuscript is an original research paper and is not being considered elsewhere. We declare that we have no conflict of interest.

\section{Acknowledgements}

We wish to express our thanks to the different organisations and institutions from which we received immense help during our study. The authors express their heartfelt gratitude to the anonymous reviewers for the minute review of the manuscript and provide valuable suggestions to improve the standard of the manuscript.

\section{Author Contribution Statement}

Sk Ismaile and Dr Namita Chakma have co-jointly designed the study. Sk Ismaile collected the data of different Census years from the official website of the Census of India. Sk Ismaile then analysed the data and wrote the first draft of the manuscript. The draft manuscript was reviewed by Dr Namita Chakma, who added further inputs to improve the quality of the manuscript. The final draft was further re-read and edited by Sk Ismaile. 